Issledovatel'skiy Zhurnal Russkogo Yazyka i Literatury, Vol. 9, Issue 2, 2021, Pp: 75-90 DOI: 10.52547/iarll.18.75 DOR: 20.1001.1.23452498.2021.9.2.4.2

\title{
Iranian Literary Criticism about Dostoevsky: Works of Fatima Sayyah
}

\author{
Kravchenko Oksana Anatolievna ${ }^{1}$
}

Adjunct Professor, Department of Russian Language, Faculty of Literature, Alzahra University, Tehran, Iran.

\section{Sadeghi Sahlabad Zeinab ${ }^{2}$ *}

Assistant professor, Department of Russian Language, Faculty of Literature, Alzahra University, Tehran, Iran.

(date of receiving: February, 2021; date of acceptance: July, 2021)

\begin{abstract}
The article is devoted to the study of the critical heritage of F. Sayyah dedicated to Dostoevsky. At first the biography of the researcher who linked the cultures of Russia and Iran with her own destiny is briefly presented. The works of the 1920s "Dostoevsky and Contemporary French Literature", "Dostoevsky in Western Criticism" are analyzed. The key methodological guidelines of the researcher are noted: the perception of Dostoevsky as a writer of a crisis era, which determined the psychological characteristics of his novels, duality as a manifestation of the spiritual instability of the heroes, dynamism as a principle of the temporal and compositional organization of the text. The position of I. Parsinezhad on the dominance of the Marxist ideological attitude in the research of F. Sayyah was critically assessed. A short article-preface to the Persian translation of the "White Nights» story is analyzed. It is indicated that the article not only reveals the artistic genius of Dostoevsky for the Iranian reader, but also contains a call to learn from him the skills of writing, to form realistic Iranian prose based on Dostoevsky. The general conclusion of the article is to affirm the relevance of the ideas of F. Sayyah for contemporary Dostoevsky studies.
\end{abstract}

Keywords: Dostoevsky, F. Sayyah, Iran, Dialogue of Cultures, Psychological Novel, Theoretical Reception.

1. E-mail: O.kravchenko@alzahra.ac.ir

2. E-mail: z.sadeghi@alzahra.ac.ir * Corresponding author 


\title{
Иранское литературоведение о Достоевском: работы Фатимы Сайях
}

\author{
Кравченко Оксана Анатольевна ${ }^{1}$
}

Профессор, Кафедра русского языка, Факультета литературы, Университет Аль-Захра, Тегеран, Иран.

\section{Садеги Сахлабад Зейнаб ${ }^{2 *}$}

Старший преподаватель, Кафедра русского языка, Факультета литературы, Университет Аль-Захра, Тегеран, Иран.

(дата получения: февраль 2021 г.; дата принятия: июль 2021 г.)

\begin{abstract}
Аннотация
Статья посвящена исследованию критического наследия Ф. Сайях, посвященного Достоевскому. Кратко представлена биография исследовательницы, объединившей собственной судьбой культуры России и Ирана. Проанализированы работы 1920-х годов «Достоевский и современная французская литература», «Достоевский в западной критике». Отмечены ключевые методологические установки исследовательницы: восприятие Достоевского как писателя кризисной эпохи, определившей особенности психологизма его романов, двойничество как проявление духовной нестабильности героев, динамизм как принцип временной и композиционной организации текста. Критически оценена позиция И. Парсинеджада о доминировании марксисткой идеологической установки в исследованиях Ф. Сайях. Проанализирована краткая статья-предисловие к персидскому переводу повести «Белые ночи». Указано, что статья не только раскрывает для иранского читателя художественный гений Достоевского, но и содержит призыв учиться у него писательскому мастерству, формировать реалистическую иранскую прозу с опорой на Достоевского. Общий вывод статьи состоит в утверждении актуальности идей Ф. Сайях для современного достоевсковедения.
\end{abstract}

Ключевые слова: Достоевский, Ф. Сайях, Иран, Диалог Культур, Психологический Роман, Теоретическая Рецепция.

1. E-mail: O.kravchenko@alzahra.ac.ir

2. E-mail: z.sadeghi@alzahra.ac.ir * Ответственный автор 


\section{Введение}

В юбилейной «Пушкинской речи» Ф. Достоевский говорил о «всемирной отзывчивости» поэта. Сегодня, в год 200-летия Достоевского, идея всемирной отзывчивости обретает новый смысл: не только писатель перевоплощает свой дух «в дух чужих народов» (Достоевский 1984. 146), но и народы впитывают в себя, принимают в состав своей собственной культуры «всемирные» (Там же. 145) идеи писателя. В юбилейной перспективе очевидно, что творчество Достоевского всесторонне изучено сквозь призму многих наук и литературоведческих методологий. Но кроме этого движения вглубь текстов и идей, наблюдалось еще и движение вширь. «Экспансия» Достоевского распространилась не только на страны Европы, но также на Азию и Америку. Удивительным образом на перекрестке этих потоков оказывается советскоиранская исследовательница Фатима Риза-Заде (в иранском научном и литературном сообществе она известна под псевдонимом мужа: Сайях; в дальнейшем мы будем указывать принятую в Иране фамилию). Её блестящие работы о Достоевском, опубликованные почти сто лет назад, и в наши дни не утратили своего эвристического потенциала. Статьи Сайях советского периода посвящены художественной и философско-критической рецепции Достоевского в Европе 1920-х годов. В то же время исследовательница является популяризатором творчества Достоевского в Иране 1930-1940х годов. Написанное ею предисловие к персидскому переводу повести «Белые ночи» не только раскрывает для иранского читателя художественный гений Достоевского, но и содержит призыв учиться у него писательскому мастерству, формировать реалистическую иранскую прозу с опорой на Достоевского. Задача настоящей статьи состоит в том, чтобы осмыслить направление исследовательских поисков Сайях, оценить ее роль в реализации всемирного влияния Достоевского. 


\section{Основная часть}

Научная и общественная деятельность Сайях предопределила, как мы полагаем, тот активный культурный интерес, которым окружено имя Достоевского в современном Иране. Помимо переводов и экранизаций (в основу сценариев легли такие произведения, как «Униженные и оскорбленные», «Белые ночи», «Преступление и наказание», «Братья Карамазовы») можно говорить также о развитии исследовательских подходов, представленных по преимуществу компаративистикой. Особо следует указать на опубликованные в Иране статьи российских авторов, задающих перспективы исследования Достоевского в семиотическом (Сафронова, 2019) и интермедиальном (Степанян, 2020) ракурсах.

Говоря о началах собственно иранского достоевсковедения, необходимо отметить деятельность Иранского общества культурных связей с СССР и издаваемого им периодического издания «Пеяме ноу» / «Пеяме новин» («Новый вестник»). В редакционную коллегию журнала входила и Ф. Сайях.

Первое заседание общества состоялось 17 мая 1944 года и было посвящено памяти Чехова. 40-летняя годовщина со дня смерти писателя послужила поводом для демонстрации того культурного прорыва, который был совершен Ираном за два десятилетия с начала появления первых переводов русской классики. «В 1944 году в связи с сорокалетием со дня смерти А.П. Чехова в иранском журнале «Паяме ноу» была напечатана статья профессора Тегеранского университета Фатимы Сайах, посвященная жизни и творчеству русского писателя, в которой звучал призыв к персидским писателям «следовать Чехову» (Карими-Мотаххар, Яхьяпур, Ашрафи 2009. 226). Уже в 1959 году литературовед Абдолали Дастагейб так описывал характер знакомства иранцев с литературой России: «Русская литература с ее блестящими поэтами, такими как Пушкин и Лермонтов, которые обладали тонким чувством восприятия и изящным слогом, а также писателями как 
Гоголь, Тургенев, Чехов, Горький, Достоевский и Толстой, способными просто и понятно раскрывать глубокие и возвышенные идеи, еще двадцать лет тому назад была для иранцев незнакомой. Было переведено на персидский язык лишь несколько стихотворений Пушкина и несколько коротких рассказа Чехова...» (Dastgheib 1959. 80). В подобной ситуации Сайях была одним из пионеров иранской русистики, и ее деятельность носила как просветительский, так и культуротворческий характер.

Сайях была уникальным ученым, объединившим собственной судьбой две страны и две культуры. Доктор филологических наук, профессор Тегеранского университета, Фатима Риза-Заде родилась в 1281/1902 году в Москве в семье известного востоковеда Мирзы Джафар-Хана Резазаде Махаллати, который 45 лет был профессором персидского языка и литературы в Институте восточных языков. Мать Фатимы имела немецкие корни. Фатима училась на филологическом факультете Московского университета. Темой её диссертации было творчество Анатоля Франса. Фатима вышла замуж за своего двоюродного брата Хамида Сайяха, окончившего юридический факультет Московского университета, и вместе с ним в 1921 году уехала в Иран. Спустя три года Фатима Сайях развелась с мужем, но сохранила его фамилию. После развода Фатима вернулась в Москву, а в 1934 г. уже окончательно переехала в Тегеран. Д. С. Комиссаров пишет, что годы, проведенные в Иране «Ф. Сайях посвятила любимому делу - исследованию и преподаванию русской литературы в Тегеранском университете (она занималась также сравнительным изучением литератур). Блестяще владея персидским и русским языками (а также европейскими), и будучи безусловно одаренной и эрудированной в области литературы, Ф. Сайях могла переводить произведения русской литературы на персидский язык с оригинала и заниматься исследованием творчества русских писателей. Ее перу принадлежат работы: “Антон Чехов”, “Достоевский”, “Восток 
в произведениях Пушкина”, “Михаил Шолохов” и др.» (Комиссаров 2005. 201).

Остановимся подробнее на исследованиях московского периода жизни Сайях, посвященных Достоевскому. Речь идет о статьях «Достоевский и современная французская литература (о влиянии Достоевского)» (Риза-Заде 1927) и «Достоевский в западной критике» (Риза-Заде 1929). Основные идеи были суммированы в написанной в соавторстве с В. Ф. Переверзевым статье «Достоевский» для Литературной энциклопедии (Переверзев, Риза-Задэ 1930).

Осмысляя причины живого интереса к Достоевскому, вспыхнувшего в Европе 1920-х голов, Сайях объясняет их историко-политическими факторами. Достоевский как писатель кризисов и катастроф стал созвучен мироощущению читателя-европейца, пережившего трагедию Первой мировой войны 1914-1918 годов. Разрыв привычных связей и отношений, шаткость положения человека в обществе и нестабильность самого общества - все это оказалось реально-жизненным аналогом художественного мира Достоевского. Вне этого экстремального опыта, еще в конце XIX века европейцы считали Достоевского талантливым, но отнюдь не гениальным писателем. Эту мысль Сайях подкрепляет мнением Мельхиора де Вогюэ, который в книге «Русский роман» 1886 г. утверждал, что Достоевский - не гений, поскольку он односторонен и страдает отсутствием чувства меры (см.: Переверзев, РизаЗадэ 1930. 409).

Эта характеристика определяет не только довоенное восприятие Достоевского в Европе, но и специфику психологизма его романов. Отмечая, что такие писатели, как Бальзак и Стендаль представляют вершины развития психологического романа, Сайях показывает ограниченность французского психологизма. Неосознанно наследуя классицистическую традицию, авторы французского психологического романа стремятся к рационалистическому объяснению поступков и мыслей своих героев. Это находит следующие 
отражения в сопоставлении поэтических принципов Бальзака и Достоевского: «Бальзак не интересуется явлениями противоречивыми и непонятными, Достоевский дает явления во всей их загадочности и сложности. Бальзак отметает все подсознательное, неясное, противоречивое. Достоевский главным образом о нем и говорит. Последовательность и ясность - вот принципы построения у Бальзака. Сохранение противоречивости, двойственности и сложности явления - вот принципы Достоевского» (Риза-Заде 1925. 36).

Исходя из этих наблюдений, исследовательница опровергает мысль В. Гроссмана о том, что роман Бальзака «Отец Горио» - «пролегомены»к «Преступлению и наказанию», а главный его герой Растиньяк - прообраз Раскольникова.

Сайях утверждает, что французский психологический роман оказался неспособен дать образ человека в состоянии мировоззренческого кризиса, поскольку в основе его поэтики остаются принципы формальной логики. Достоевский же передает саму психологическую динамику, нестабильность, спонтанность, порыв.

Подобные рассуждения Сайях обнаруживают стиль глубокого и оригинального исследователя, стремящегося идти в науке собственным путем. Поэтому нам представляются предвзятыми суждения современного литературоведа Ираджа Парсинеджада о том, что научная деятельность Сайях была скована рамками марксисткой идеологи: «... ее ориентация на марксистскую критику и приверженность школе социалистического реализма неблагоприятно сказались на способности критически оценивать литературу; наиболее ярким проявлением пагубного влияния соцреализма стало то, что такие выдающиеся писатели, как Марсель Пруст и Джеймс Джойс оказались вне поля зрения исследовательницы» (Parsi-Nejad 2010. 187). Бесспорно, мировоззренческой основой суждений Сайях был марксизм, однако это совсем не означало, что марксизмом подменялся литературоведческий анализ текста, 
глубину и проницательность которого в полной мере демонстрирует статья «Достоевский и французская литература». Здесь стоит также вспомнить, что сам Марсель Пруст формировался под влиянием Стендаля, Флобера, Достоевского и Толстого - то есть того самого реалистического направления, за приверженность которому Парсинеджад неустанно попрекает Сайях.

Обратим также внимание на различия подходов, отраженные в энциклопедической статье «Достоевский». Первая ее часть написана В. Ф. Переверзевым - основателем марксистского направления в советском литературоведении. Исследователь считает Достоевского представителем мещанского сословия. В сравнении Достоевского с Пушкиным Переверзев актуализирует категории общественных классов: Пушкин представляет дворянство, «помещичье слово», утратившее свое социально-культурное влияние в 40-60x годах XIX века, Достоевский же предстает выразителем идей полунищей интеллигенции и мещан: «Все писатели дворянского периода в большей или меньшей степени сродни Пушкину; все писатели буржуазного периода русской литературы в большей или меньшей степени сродни Достоевскому» (Переверзев, Риза-Задэ 1930. 407).

Раздел же, написанный Сайях, выстраивается на анализе исторической ситуации Европы начала XX века и ключевых поэтических характеристик Достоевского, усвоенных французской литературой: психологизм, двойничество, сюжетная и композиционная динамика.

К этому следует добавить, что марксистское направление не было тупиковым путем развития литературоведения. В его арсенале классовый анализ общества служил историко-культурным основанием для осмысления таких проблем, как образная и сюжетная специфика, композиция, жанр, стиль, пейзаж, портрет и др. Как сказано в Краткой литературной энциклопедии о деятельности В. Переверзева, его работам, не смотря на социологический уклон, «свойствен тонкий анализ художественной структуры текста, глубокое 
проникновение в систему образов художественного произведения» (Белкин 1968. 655).

О том, что в статьях Сайях мы не сталкиваемся с упрощением и схематизацией историко-литературного процесса, что как ученый она обладала независимостью суждений свидетельствует ее обращение к религиозной проблематике творчества Достоевского. Рассматривая факты поэтического воздействия Достоевского на французских писателей, исследовательница отмечает, что Европа оказалась не способна постичь духовно-художественный потенциал таких героев Достоевского, как князь Мышкин, старец Зосима, Алеша Карамазов. Если убийцы, одержимые идеей наполеонизма, двойники и бунтари - все эти образы кризисного сознания у Достоевского находят свою разработку в литературе XX века, то герои, подобные Князю Христу, несущие в себе свет любви и прощения, оказываются непереводимы в контекст европейского мировосприятия. Согласно мнению Яхьяпур «Достоевский преодолевает границы, чтобы постичь истину. Он как проповедник гуманности, считает, что спасение человечества возможно в религиозных убеждениях» (Yahyapour 2006. 147).

Указанные особенности научного подчерка Сайях Парсинеджад не учитывает в своей жесткой критике. Отдельные его положения заимствуют худшие черты вульгарного социологизма: «Фатима Сайях, воспитанная школьной системой Советского Союза и находившаяся под влиянием доктринальных принципов и идей Жданова, секретаря ЦК Коммунистической партии и его теоретика, верит в реализм Чернышевского...» (Parsi-Nejad 2010. 188). Отметим, что ждановская эпоха, действительно губительная для русской культуры, началась с осуждения творчества Ахматовой и Зощенко в августе 1946 года, - то есть за полтора года до смерти иранской исследовательницы. Хронология вскрывает предвзятость суждений Парсинеджада, помнящего о Жданове, но забывающего о культурном взлете 1920-х годов, породившем и формальный метод в литературоведении, и витебский кружок Бахтина, и 
деятельность Вольфилы (Вольной философской ассоциации). Именно в этом интеллектуальном котле российских 1920-х годов происходило научное становление Сайях, не сводимое без остатка к марксизму.

Bсе это заставляет признать, что в единственном на сегодняшний день исследовании, посвященном деятельности Сайях, на первый план выходят необоснованные упреки в приверженности марксистской идеологии и методологии литературоведческого анализа. Однозначно одобрительно Парсинеджад отзывается исключительно о педагогической деятельности Сайях.

Широта научных взглядов Сайях многократно превышала стандарты советской образовательной системы. Свободное владение европейскими языками (французским, английским, немецким и итальянским) позволило молодой еще исследовательнице написать блестящий критический очерк «Достоевский в западной критике» (Риза-Заде 1929), сосредоточив внимание на немецкой интеллектуальной рецепции Достоевского. Сам подход к систематизации материала отражает понимание сложности феномена Достоевского, и в наши дни еще воспринимаемого не как художник, а как идеолог и мыслитель.

Обзор исследовательницы открывается панорамным взглядом на проблему. Bсе работы о Достоевском она подразделяет на несколько групп, как по принципу подхода к творчеству Достоевского, так и по общей методологической установке. Резкая критика исследовательницы направлена на работы философского характера, трактующие мировоззрение Достоевского исключительно с отвлеченно-философской точки зрения. Не принимая прочтения творчества Достоевского как зеркала мировоззрения, идеологии и психологии самого писателя, Сайях как бы заранее отвечает и на инвективы собственных критиков: «Нельзя не подчеркнуть, насколько вообще спорно положение о возможности подхода к художнику не как к таковому, а как-то иначе, минуя его художественное творчество, или выбирая из него некоторый 
комплекс идей» (Риза-Заде 1929. 143). Исследовательница постоянно задает вопрос: в чем выражается собственно литературное влияние Достоевского?

С точки зрения Сайях новаторство Достоевского состоит в том, что он первым нашел приемы изображения психологии человека эпохи кризиса. «Достоевский первый сумел воплотить психику этого человека, со всеми ее противоречиями, не упрощая и не устраняя этих противоречий. Он первый подошел диалектически к психологическому анализу своих героев <..> Вот почему растет влияние Достоевского. И это влияние нужно анализировать в чисто-литературном плане, так как Достоевский велик именно как художник и ничем другим, кроме художника, не является и именно, как таковой, и должен восприниматься» (Там же. 175).

Эта установка изучать Достоевского как художника показывает, что и для самой исследовательницы первичны были художественные, a не идеологические и конъюнктурные подходы к тексту.

В Иране вышла еще одна небольшая работа, посвященная Достоевскому. Это было предисловие к переводу повести «Белые ночи», осуществленному Захрой Ханлари (см.: Sayyah 1945). Здесь Сайях знакомит персидского читателя с биографией Достоевского и особенностями его стиля, показывает духовную эволюцию писателя: от революционных идей к богоискательству. Сайях раскрывает значение знаменитого тезиса Достоевского: «Тут дьявол с Богом борется, а поле битвы - сердца людей» (Достоевский 1976. 100). Общим знаменателем произведений Достоевского, как подчеркивает Парсинеджад, Сайях считает сочувствие человеческой боли (Parsi-Nejad 2010. 157). Достоевский предстает как художник, мастерски изображающий физические и душевные страдания людей. В его романах - сочувствие к униженным и оскорбленным, чьи разговоры и внутренние монологи писатель воспроизводит во всей психологической глубине. Как можно видеть, в двухстраничном предисловии Сайях в популярной форме изложила те идеи, которые были разработаны ею еще в Москве. 
«Достоевский был и остается в ряду тех русских писателей, которые заняли очень важное место в культурной жизни современного Ирана. Это естественно: Глубина мысли, грандиозность философских построений, отразившиеся в произведениях Достоевского, имеют огромное значение для всего современного человечества» (Яхьяпур, Карими-Мотаххар 2006. 186). Достоевский стал одним из тех писателей, изучению которого была посвящена вся жизнь русско-иранской исследовательницы. Даже в сообщении о ее смерти возникает образ Достоевского: «Ф. Сайях умерла в четверг, 4 марта 1948 года. В прошлый четверг она выступила в “Ассоциации культурных связей Ирана и Франции” с докладом о влиянии Достоевского, известного русского писателя, на французскую литературу» (Ganbari 2007, 35). Причиной смерти Фатимы Сайях стал сердечный приступ, спровоцированный диабетом. Исследовательница похоронена в Тегеране на кладбище Ибн Бабавие. Согласно завещанию более 2000 книг из библиотеки ученого были переданы библиотеке факультета литературы Тегеранского университета.

\section{Заключение}

Научное наследие Сайях оказалось сегодня на периферии академической науки как в России, так и в Иране. Знакомство с ним осложнено рядом исторических факторов, в числе которых - немногочисленность сохранившихся публикаций в советской периодике второй половины 1920-х годов и отсутствие оригинальных русскоязычных текстов лекций и статей, написанных в Тегеране.

В рамках заявленного в данной публикации проблемного спектра следует отметить, что исследовательница внесла уникальный вклад в достоевсковедение. Не только для своего времени, но и почти сто лет спустя являются актуальными идеи ученого о новаторстве Достоевского в раскрытии психологии героя в состоянии кризиса, о динамическом характере сюжетнокомпозиционного построения, об избирательном наследовании 
художественных приемов Достоевского в литературе Франции начала XX века и о необоснованности сведения творчества Достоевского к философской проблематике, отразившееся в немецкой рецепции его творчества. Поставленная в статье задача осмысления исследовательских поисков Сайях нашла свое решение в анализе ее статей о Достоевском как советского, так и иранского периодов.

Филологическая эрудиция Сайях принесла в иранскую науку о литературе глубоко освоенную проблематику европейских исследований. Роль Сайях в популяризации Достоевского в Иране сводится не только к составлению предисловия к переводу «Белых ночей», но и к призыву осваивать методы реалистической прозы на материале творчества русского писателя. Перспективой данной статьи мы считаем расширение представлений о незаслуженно забытом ученом, привившем современной иранской литературе любовь к русской классике и обогатившем иранское литературоведение методологией социально-психологического анализа.

\section{Литература}

1- Белкин А.А. (1968). Переверзев // Краткая литературная энциклопедия / Гл. ред. А. А. Сурков, 1962-1978. Т. 5. - Стб. 654-655. - М.: Сов. энцикл..

2- Достоевский Ф.М. (1976). Полное собрание сочинений: В 30 m. - Т. 14. Братья Карамазовы: Роман в 4 ч. с эпилогом. Кн. 1-10. Л.: Наука.

3- Достоевский Ф.М. (1984). Полное собрание сочинений: В 30 m. - Т. 26. Дневник писателя, 1877, сентябрь-декабрь - 1880, август. Л.: Наука.

4- Карими-Мотаххар Дж., Яхьяпур М., Ашрафи Ф. (2009). К восприятию чеховской традиџии в иранской литературе (Крестьянская тема в «Мужиках» А.П. Чехова и «Шур Абаде» М. Джамаль-заде // Русская литература. № 2. С. 224-231. Санкт-Петербург: «Наука».

5- Комиссаров Д. С. (2005). [Чехов в Иране]: Обзор // Чехов и мировая литература / АН СССР. Ин-т мировой лит. им. А. М. Горького. 2005. - Кн. 3. — С. 195-213. — (Лит. наследство; Т. 100). — М.: ИМЛИ РАН.

6- Переверзев В., Риза-Задэ Ф. (1930). Достоевский Ф. М. // Литературная энциклопедия: В 11 т. — [М.], Т. 3.— Стб. 396-410. — [М.]: Изд-во Ком. Акад. 
7- Риза-Заде Ф. (1927). Достоевский и современная франиузская литература (о влиянии Достоевского) // Печать и революция. № 6. С. 34-52.

8- Риза-Заде Ф. (1929). Достоевский в западной критике // Литература и марксизм, кн. III. С. $139-176$.

9- Сафронова Е. (2019). Топос усадебного рая в романе Ф.М. Достоевского «Село Степанчиково и его обитатели». Исследовательский Журнал Русского Языка и Литературы, 7(2), 169-186. https://doi.org/10.29252/iarll.13.2.169

10- Степанян Е. (2020). Пластическое начало в словесности. Роман Достоевского «Бесы». Исследовательский Журнал Русского Языка и Литературы, 8(2), 187-202. https://doi.org/10.29252/iarll.16.195

11- Яхьяпур М., Карими-Мотаххар Дж. (2006). “Двойник» Ф.М. Достоевского и «Слепая сова» С. Хедаята // Русская литература. № 3. С. 185-189, СанктПетербург: «Наука».

12- Dastgheib Abdul-Ali. (1338/1959). Translations of Russian literature into Persian // Payame novin. No. 11-12, pp. 80-83. [In Persian]

13- Ganbari Omid. (1386/2007). Biography of Dr. Fatemeh Sayyah, Tehran: Association of Cultural Works and Honors. 173 p. [In Persian]

14- Parsi-Nejad Iraj. (1389/2010). Fatemeh Sayyah and Literary Criticism. Tehran: Sokhan. 255 p. [In Persian]

15- Sayyah Fatemeh. Dostoevsky (Introduction to the book "Bright Nights") // Sokhan, vol. 2. pp. 23-27. Tehran: Sokhan. [In Persian]

16- Yahyapour M. (1385/2006). A Study of Islamic Concepts in Some of Theodore Dostoyevsky's Works and the Reasons for his Interest in these Concepts, Pazhuheshe Zabanha-ye Khareji, № 30, Spering, Pp145-159. [In Persian]

\section{Bibliography}

1- Belkin A.A. (1968). Pereverzev // Kratkaja literaturnaja jenciklopedija / Gl. red. A. A. Surkov, 1962-1978. T. 5. — Stb. 654-655. — M.: Sov. jencikl..

2- Dostoevskij F.M. (1976). Polnoe sobranie sochinenij: V 30 t. - T. 14. Brat'ja Karamazovy: Roman v 4 ch. s jepilogom. Kn. 1-10. L.: Nauka.

3- Dostoevskij F.M. (1984). Polnoe sobranie sochinenij: V 30 t. - T. 26. Dnevnik pisatelja, 1877, sentjabr'-dekabr' - 1880, avgust. L.: Nauka.

4- Karimi-Motahhar Dzh., Jah'japur M., Ashrafi F. (2009). K vosprijatiju chehovskoj tradicii v iranskoj literature (Krest'janskaja tema v «Muzhikah» A.P. Chehova $i$ «Shur Abade» M. Dzhamal'-zade // Russkaja literatura. № 2. S. 224-231. SanktPeterburg: «Nauka». 
5- Komissarov D. S. (2005). [Chehov v Irane]: Obzor // Chehov i mirovaja literatura / AN SSSR. In-t mirovoj lit. im. A. M. Gor'kogo. 2005. — Kn. 3. — S. 195-213. (Lit. nasledstvo; T. 100). - M.: IMLI RAN.

6- Pereverzev V., Riza-Zadje F. (1930). Dostoevskij F.M. // Literaturnaja jenciklopedija: V 11 t. — [M.], T. 3.— Stb. 396 - 410. — [M.]: Izd-vo Kom. Akad.

7- Riza-Zade F. (1927). Dostoevskij i sovremennaja francuzskaja literatura (o vlijanii Dostoevskogo) // Pechat' i revoljucija. № 6. S. 34-52.

8- Riza-Zade F. (1929). Dostoevskij v zapadnoj kritike // Literatura i marksizm, kn. III. S. $139-176$.

9- Safronova E. (2019). Topos usadebnogo raja v romane F.M. Dostoevskogo «Selo Stepanchikovo $i$ ego obitateli». Issledovatel'skij Zhurnal Russkogo Jazyka i Literatury, 7(2), 169-186. https://doi.org/10.29252/iarll.13.2.169

10- Stepanjan E. (2020). Plasticheskoe nachalo v slovesnosti. Roman Dostoevskogo «Besy». Issledovatel'skij Zhurnal Russkogo Jazyka i Literatury, 8(2), 187-202. https://doi.org/10.29252/iarll.16.195

11- Jah'japur M., Karimi-Motahhar Dzh. (2006). «Dvojnik» F.M. Dostoevskogo $i$ «Slepaja sova»S. Hedajata // Russkaja literatura. № 3. S. 185-189, SanktPeterburg: «Nauka».

12- Dastgheib Abdul-Ali. (1338/1959). Translations of Russian literature into Persian // Payame novin. No. 11-12, pp. 80-83. [In Persian]

13- Ganbari Omid. (1386/2007). Biography of Dr. Fatemeh Sayyah, Tehran: Association of Cultural Works and Honors. 173 p. [In Persian]

14- Parsi-Nejad Iraj. (1389/2010). Fatemeh Sayyah and Literary Criticism. Tehran: Sokhan. 255 p. [In Persian]

15- Sayyah Fatemeh. Dostoevsky (Introduction to the book "Bright Nights") // Sokhan, vol. 2. pp. 23-27. Tehran: Sokhan. [In Persian]

16- Yahyapour M. (1385/2006). A Study of Islamic Concepts in Some of Theodore Dostoyevsky's Works and the Reasons for his Interest in these Concepts, Pazhuheshe Zabanha-ye Khareji, № 30, Spering, Pp145-159. [In Persian]

\section{HOW TO CITE THIS ARTICLE}

Kravchenko O.A., \& Sadeghi Sahlabad Z. (2021). Iranian Literary Criticism about Dostoevsky: Works of Fatima Sayyah. Issledovatel'skiy Zhurnal Russkogo Yazyka I Literatury, 9(2), 75-90.

DOI: $10.52547 /$ iarll.18.75

URL: https://journaliarll.ir/index.php/iarll/article/view/201

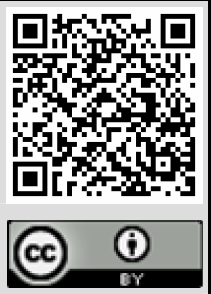




\title{
ادبياتشناسى ايران دربارةٔ داستايفسكى: آثار فاطمه سياح
}

\author{
آكسانا آناتولى يونا كر افجنكو'

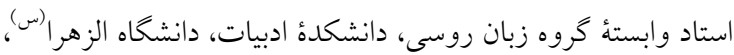

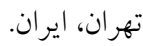

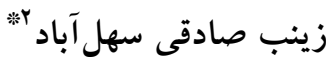

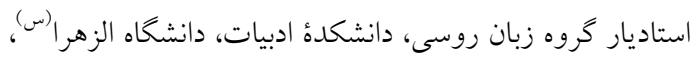

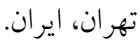

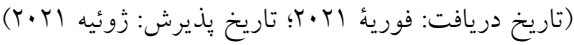

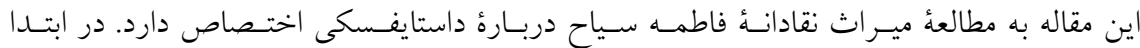

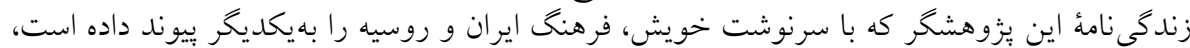

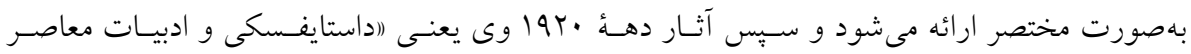

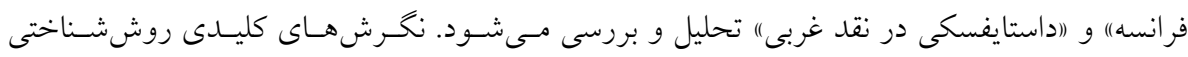

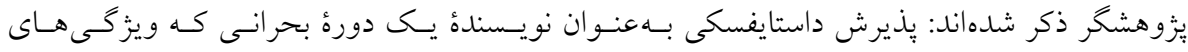

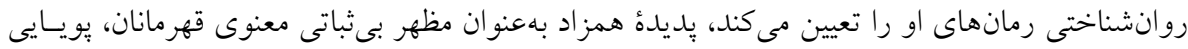

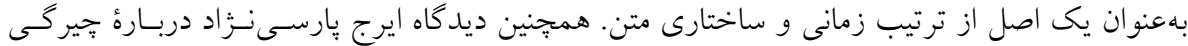

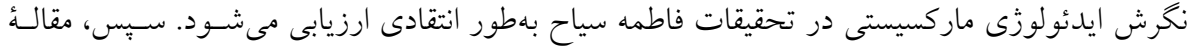

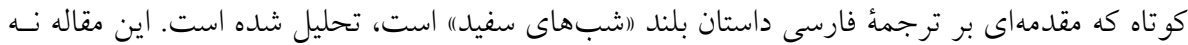

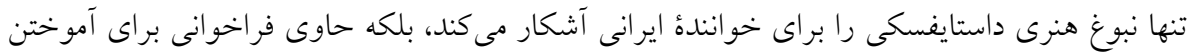

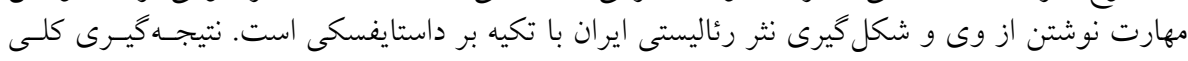

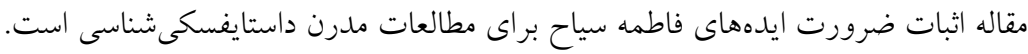

وازگًان كليدى: داستايفسكى، فاطمه سياح، ايران، كفتو گوى فرهنخها، رمـان روانشـناختى،

درى نظرى.

1. E-mail: O.kravchenko@alzahra.ac.ir

2. E-mail: z.sadeghi@alzahra.ac.ir نويسنده مسئول * نوع مقاله: علمى - يزووهشى 